\title{
Ruthenium Electrodeposition from Deep Eutectic Solvents
}

\author{
R. Bernasconi, $\oplus^{1, *}$ A. Lucotti, ${ }^{2}$ L. Nobili, ${ }^{1}$ and L. Magagnin ${ }^{1, * *, z}$
}

${ }^{1}$ Dipartimento di Chimica, Materiali e Ingegneria Chimica Giulio Natta, Politecnico di Milano, 20131 Milan, Italy

${ }^{2}$ Dipartimento di Chimica, Materiali e Ingegneria Chimica Giulio Natta, Politecnico di Milano, 20133 Milan, Italy

\begin{abstract}
Ruthenium is electrodeposited for the first time from a deep eutectic solvent based electrolyte composed of ethylene glycol and choline chloride in 1:2 molar ratio. Deposition is found to effectively occur upon addition of sulfamic acid to the Ru(III) containing deep eutectic solvent. The main consequence of the presence of sulfamic acid, as evidenced by the electrochemical characterization performed, is the oxidation of $\mathrm{Ru}(\mathrm{III})$ to $\mathrm{Ru}(\mathrm{IV})$. Consequently, Ru electroreduction is demonstrated to take place from the tetravalent state. Optimized plating conditions are able to yield uniform and crack-free Ru coatings up to $800 \mathrm{~nm}$ thickness. No oxides or other notable secondary phases can be individuated in the obtained metallic layers. Morphological and electrical properties of the layers obtained are comparable with Ru coatings deposited from sputtering and suggest possible applications in the electronics field as barrier layers for interdiffusion.

(C) The Author(s) 2018. Published by ECS. This is an open access article distributed under the terms of the Creative Commons Attribution 4.0 License (CC BY, http://creativecommons.org/licenses/by/4.0/), which permits unrestricted reuse of the work in any medium, provided the original work is properly cited. [DOI: 10.1149/2.0541813jes]

(c) BY
\end{abstract}

Manuscript submitted August 7, 2018; revised manuscript received September 14, 2018. Published September 26, 2018. This was Paper 972 presented at the National Harbor, Maryland Meeting of the Society, October 1-5, 2017.

Ruthenium, a transition metal belonging to the same group of platinum, ${ }^{1}$ is used nowadays in many different industrial applications: decorative and corrosion resistant coatings, wear protection for electrical contacts ${ }^{2,3}$ and interdiffusion barrier layers. ${ }^{4,5}$ Moreover, interesting catalytic properties have been demonstrated for this bright white metal both in its metallic form ${ }^{6}$ and as oxide. ${ }^{7}$ Ruthenium broad range of applications is a direct consequence of its interesting technological properties, such as good chemical inertness in most environments, high melting point and a considerably high hardness. Ruthenium based barrier layers for microelectronic applications, in particular, constitute an application that is gaining significant attention in the modern electronic industry. ${ }^{8,9}$ Indeed, interdiffusion between copper interconnects used in modern integrated circuits (IC) technology and silicon from the wafers can be efficiently limited employing nanometric layers of ruthenium instead of current state-of-the-art materials like $\mathrm{Ta} / \mathrm{TaN}{ }^{10}$ or TiN. ${ }^{11}$ The reason for the high shielding efficiency of ruthenium can be found in its extremely low miscibility with copper and in the absence of intermetallics in the $\mathrm{Cu}-\mathrm{Ru}$ phase diagram. ${ }^{12}$

Ruthenium layers can be applied using many techniques, including physical vapor deposition (PVD) ${ }^{4}$ or chemical vapor deposition (CVD). ${ }^{13}$ However, wet metallization techniques offer the best benefits in terms of productivity, scalability and cost per unit. In particular, the electrolytic deposition technique is of great interest from the industrial point of view due to its simplicity and low cost. Commercially, ruthenium electrodeposition typically takes place from aqueous sulfamate based electrolytes containing the metal in the form of a bridged complex known as $\mu$-nitridobisaquatetrachlororuthenate $\left[\mathrm{Ru}_{2}(\mu-\mathrm{N})\left(\mathrm{H}_{2} \mathrm{O}\right)_{2} \mathrm{Cl}_{8}\right]{ }^{14-16}$ Deposition from these baths is characterized by a good cathodic efficiency (exceeding 90\%) and by crack-free deposits up to 1-2 $\mu \mathrm{m}$ thickness. Sulfamate based electrolytes are virtually the only $\mathrm{Ru}$ plating electrolytes that find practical application, since alternative aqueous formulations are normally characterized by poor cathodic efficiency or unsuitable morphology ${ }^{17}$ However, ruthenium tends to oxidize in aqueous environment ${ }^{18}$ and resulting deposits can contain impurities or oxides. This property can be advantageous if the final goal is to achieve ruthenium oxides deposition ${ }^{19-21}$ in aqueous environment for catalysis applications, but it represents a serious limitation for the electrodeposition of metallic ruthenium. Moreover, deposition from aqueous solutions in general is not optimal to directly apply coatings on reactive substrates like aluminum, ${ }^{22}$ which require specific pretreatments.

Deep eutectic solvents (DESs) have been proposed as alternative electrolytes to overcome aqueous solutions limitations. ${ }^{23,24}$ Wide

\footnotetext{
*Electrochemical Society Student Member.

**Electrochemical Society Member.

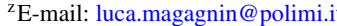

potential window, high metal ions solubility and high conductivities are the properties typical of DESs that can be exploited in electrodeposition. Four classes of $\mathrm{DES}^{23}$ are present in the current literature: group I includes DESs formed between a quaternary ammonium salt and an anhydrous metal halide, group II contains DESs analogous to group I but in this case the metal halide is hydrated, group III comprises DESs formed mixing a quaternary ammonium salt and an hydrogen bond donor, group IV is constituted of mixtures of metal halides and hydrogen bond donors. Group III DESs are suitable electrolytes for the deposition of the most common metals, ${ }^{25}$ including $\mathrm{Cu}^{26} \mathrm{Zn}^{24}{ }^{24} \mathrm{Ni}^{27} \mathrm{Fe}^{28}$ Moreover, DESs can be used to deposit alloys $^{29,30}$ and composites ${ }^{31}$ as well. Ruthenium has never been electrodeposited from DESs, while it has been deposited from water and air stable ionic liquids (ILs) based on 1-butyl-3-methyl-imidazolium (BMIM) hexafluorophosphate ${ }^{32}$ and 1-butyl-3-methylimidazolium dicyanamide. ${ }^{33}$ The electrochemical behavior of $\mathrm{Ru}(\mathrm{III})$ was investigated also in 1-butyl-3-methylimidazolium chloride, ${ }^{34,35}$ and electrodeposition has been characterized as well. Air and water stable ILs are however less environmentally friendly than DESs and they require more controlled deposition conditions. For this reason, the individuation of a deposition procedure for ruthenium from DESs is an attractive topic in modern non-aqueous electrochemistry.

The aim of the present paper is the investigation of ruthenium electrodeposition from a DES obtained mixing choline chloride and ethylene glycol in 1:2 molar ratio. This DES, belonging to the class III and commercially known as ethaline, is characterized by interesting physical and chemical properties and it constitutes a good electrolyte for the deposition of many metals. Deposition is optimized and resulting coatings are characterized to exclude the possible presence of oxides or other secondary phases. Moreover, the possible application of $\mathrm{Ru}$ electrodeposition from DESs for barrier layers manufacturing is investigated by depositing $\mathrm{Ru}$ on seeded silicon wafers.

\section{Experimental}

All the chemicals used during the experimentation were acquired from Sigma Aldrich. Most of such chemicals were used as received, except $\mathrm{RuCl}_{3} \cdot \mathrm{nH}_{2} \mathrm{O} . \mathrm{RuCl}_{3} \cdot \mathrm{nH}_{2} \mathrm{O}$ was dried according to a procedure available in literature ${ }^{36}$ to limit the presence of oxo- or hydroxychloro complexes and nitrosyl species. The material was initially dried for $3 \mathrm{~h}$ at $120^{\circ} \mathrm{C}$. During this first step, ruthenium chloride lost significant quantities of water. The resulting mass was then ground in a mortar and again heated at $120^{\circ} \mathrm{C}$ for $1 \mathrm{~h}$. Anhydrous $\mathrm{RuCl}_{3}$ was then stored in a desiccator to avoid moisture adsorption. Choline chloride $(\mathrm{ChCl})$ was mixed with ethylene glycol (EG) in a 1:2 molar ratio to obtain the base DES electrolyte. $\mathrm{RuCl}_{3}$ in different amounts (20 or $40 \mathrm{mM}$ ) was then added to form the plating solution, which 
a)
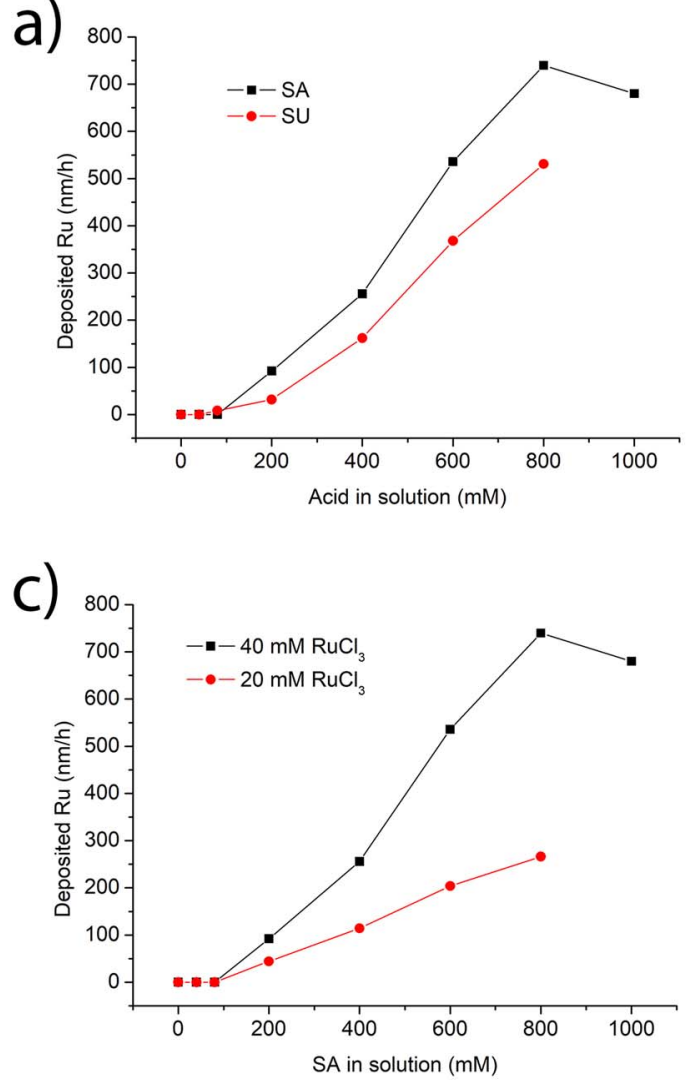
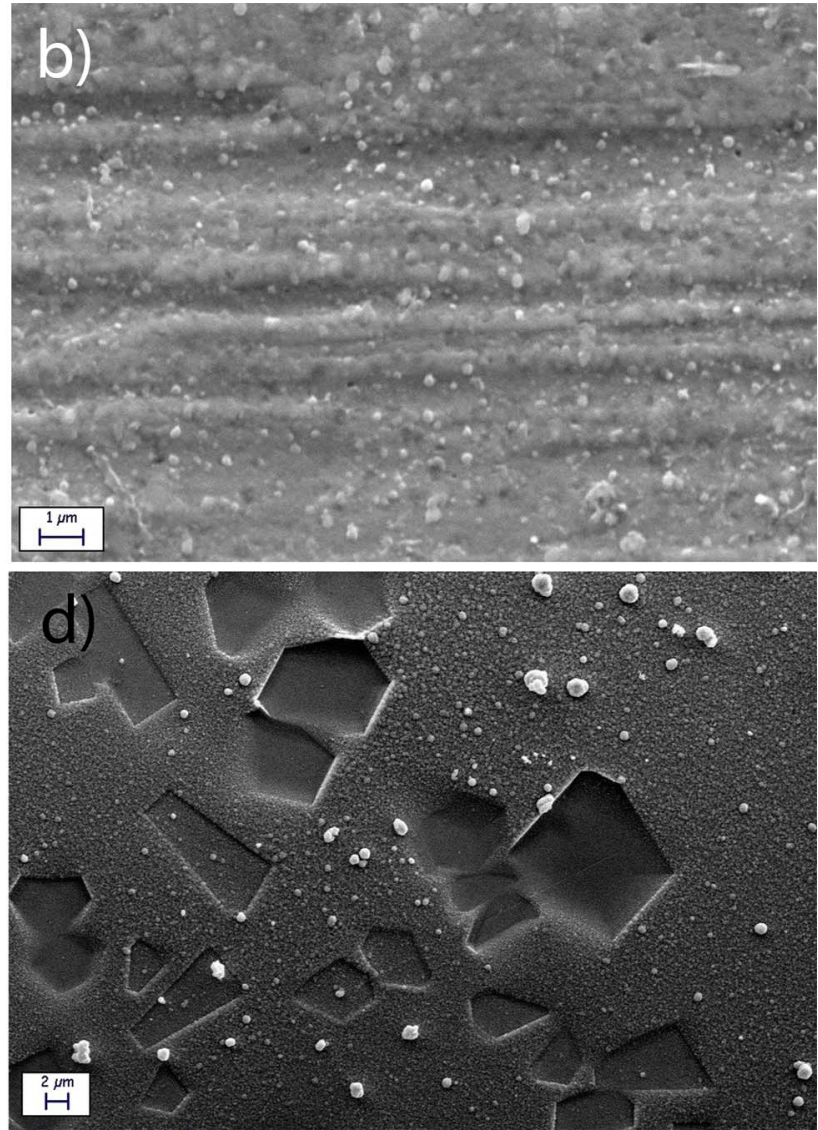

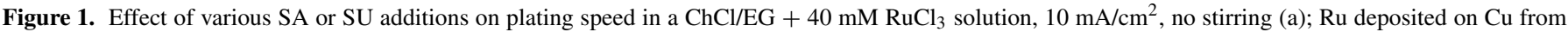

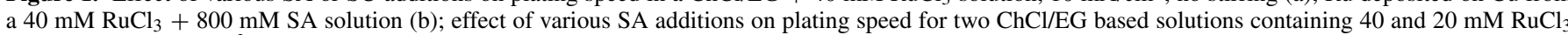
respectively, $10 \mathrm{~mA} / \mathrm{cm}^{2}$, no stirring (c); Ru deposited on Au sputtered on Si from a $40 \mathrm{mM} \mathrm{RuCl} 3+800 \mathrm{mM} \mathrm{SA}$ solution (d).

was stirred for $12 \mathrm{~h}$ to completely homogenize. Where used, sulfamic acid (SA) was added in variable amounts and the solution was stirred for $12 \mathrm{~h}$ to completely homogenize. All plating baths were employed at $80^{\circ} \mathrm{C}$. Plating parameters are detailed in the results and discussion part. Where employed, agitation was provided using magnetic stirring. $\mathrm{Cu}$ sheets and $\mathrm{Au}(120 \mathrm{~nm}$ thickness) sputtered on ultraflat $\mathrm{Si}$ wafers were used as substrates after cleaning with acetone. $\mathrm{Cu}$ oxide was removed immersing $\mathrm{Cu}$ substrates in a $5 \% \mathrm{HNO}_{3}$ solution for $1 \mathrm{~min}$. Cathodic efficiency was evaluated by calculating the amount of deposited material from the thickness of the coatings. Electrolytes conductivity was measured employing a parallel Pt plates Amel 160 conductivimeter. Cyclic voltammetry (CV) was performed on the solutions using glassy carbon as working electrode, a Pt wire as reference and graphite as counter. All the voltammetric tests were performed using an AMEL 2550 galvanostat/potentiostat. $\mathrm{Pt}$ is widely recognized as quasi-reference electrode ${ }^{37}$ and it was employed in this case due to the high temperature of the solution and to its significant $\mathrm{Cl}^{-}$content (which may damage normal commercial reference electrodes). Potential was ranged between +2 and $-3 \mathrm{~V}$ during the $\mathrm{CV}$ tests and no stirring was employed. Ru thickness was measured using a XRF X-RAY XAN apparatus by Fischerscope. AFM was performed employing a NT-MDT SOLVER PRO (in tapping mode). For SEM characterization, a Zeiss EVO 50 EP was used. Such SEM setup was equipped with an energy dispersive X-ray analyzer (EDS) Model 7060 from Oxford Instruments. XRD analysis was performed using a Philips Xpert MPD in thin films configuration with $\mathrm{Cu} \mathrm{K} \alpha=1.5406 \AA$. UV-VIS spectroscopy was carried out using a Jasco V570 spectrometer. Glow discharge optical emission spectroscopy (GDOES) was performed using a Model GDA 750 analyzer by Spectrum Analytic Gmbh. To obtain the substrates used for electrical characterization, $10 \mathrm{~nm}$ of $\mathrm{Ru}$ were sputtered on ultraflat $\mathrm{Si}$ wafers. $\mathrm{Ru} / \mathrm{Si}$ substrates were immersed, before Ru deposition, in a $10 \mathrm{~g} / \mathrm{l}$ sulfamic acid solution to remove any oxide layer present on the surface. Finally, sheet resistance of films deposited on $\mathrm{Si}$ was measured by mean of a linear 4 points probe setup.

\section{Results and Discussion}

$\boldsymbol{R} \boldsymbol{u}$ deposition optimization.--Initially, galvanostatic ruthenium electrodeposition was attempted from a mixture of $\mathrm{ChCl} / \mathrm{EG}$ and $40 \mathrm{mM} \mathrm{RuCl}_{3}$. Copper was used as substrate and current density was varied over a broad range, but no reproducible ruthenium plating was achieved. It was observed, in particular, that Ru deposition took place in an unpredictable way, with some batches of the same bath depositing Ru at extremely low current efficiencies and some others depositing no $\mathrm{Ru}$ at all. In the cases where electrodeposition took place, the copper substrate was covered irregularly with gray areas. It was however not possible to achieve efficient and reproducible ruthenium deposition in the conditions described. The chemistry of the plating bath was therefore modified in an attempt to obtain stable $\mathrm{Ru}$ deposition. According to existing literature, ${ }^{33}$ Ru deposition in ILs like BMIM based electrolytes has, as necessary prerequisite, the formation of $\mathrm{Ru}(\mathrm{IV})$ complexes. Moreover, aqueous Ru plating takes place from a $\mathrm{Ru}(\mathrm{IV})$ complex (the $\mu$-nitridobisaquatetrachlororuthenate). For these reasons, the possibility to use an acid to oxidize $\mathrm{Ru}$ (III) to $\mathrm{Ru}(\mathrm{IV})$ was examined. In particular, sulfamic acid (SA) was used in variable amounts. This acid is a typical component of aqueous $\mathrm{Ru}$ plating solutions, ${ }^{15}$ as it is necessary to form the bridged nitride complex. SA was therefore employed also for the DES electrolyte. Figure 1a clearly shows the effect of different sulfamic acid additions to a $40 \mathrm{mM} \mathrm{RuCl}_{3}$ solution in $\mathrm{ChCl} / \mathrm{EG}$. No stirring was used 
to acquire the data presented in Figure 1a and the current used for deposition was kept constant at $10 \mathrm{~mA} / \mathrm{cm}^{2}$. It can be noticed that, exceeding a threshold concentration of about $80 \mathrm{mM}$, addition of SA triggered $\mathrm{Ru}$ deposition. Further increase of SA concentration improved plating speed and efficiency, up to a maximum at $800 \mathrm{mM} \mathrm{SA}$. After this concentration, it became difficult to completely dissolve SA in the DES. For this reason, deposition speed reached a plateau after $800 \mathrm{mM}$. Accordingly, $800 \mathrm{mM}$ SA was selected as optimal concentration for the following experiments presented in the paper. Oxidation of $\mathrm{Ru}(\mathrm{III})$ to $\mathrm{Ru}(\mathrm{IV})$ and potential formation of $\mathrm{Ru}(\mathrm{IV})$ bridged complexes analogous to the one observed in water can be possible reasons for the deposition of Ru only after addition of sulfamic acid to the bath. To perform a first validation of these two options, the same procedure was repeated using sulfuric acid (SU) in place of SA. Sulfuric acid is a strong oxidant, but lacks the nitrogen moiety necessary to form the bridge between the two ruthenium atoms in the $\mu$-nitridobisaquatetrachlororuthenate complex. As visible in Figure 1a, also SU triggered Ru deposition after a threshold concentration in a way similar to SA. This result constitutes a first evidence that the formation of the bridged complex is not at the base of Ru deposition in the DES and it suggests that the oxidizing action of the acid added to the bath is the key factor to achieve reproducible deposition. The two acids produce similar effects on the chemistry of the plating bath, oxidizing $\mathrm{Ru}(\mathrm{III})$ to $\mathrm{Ru}(\mathrm{IV})$.

Since $\mathrm{RuCl}_{3}$ solubility in the DES is considerably low, only concentrations up to $40-50 \mathrm{mM}$ can be achieved. Under these conditions, considering also the comparatively high viscosity of the $\mathrm{ChCl} / \mathrm{EG}$ DES, deposition is strongly limited by the concentration of ruthenium ions present in the solution. Figure 1c shows the effect of progressive SA additions on two solutions containing 40 and $20 \mathrm{mM} \mathrm{RuCl}_{3}$ respectively. In both cases, Ru deposition took place at high enough SA concentrations, but deposition rates were significantly different. The solution containing less ruthenium trichloride was characterized by lower plating rates, compatible with the comparatively low concentration of ruthenium ions. Deposition was attempted from the $40 \mathrm{mM}$ $\mathrm{RuCl}_{3}$ solution, which maximizes the growth rate. $\mathrm{Ru}$ layers obtained at $10 \mathrm{~mA} / \mathrm{cm}^{2}$ and $30 \mathrm{~min}$ of deposition on copper without stirring were characterized by a uniform appearance and a gray color. Their microstructure, visible in Figure 1b at the SEM, was fine grained and crack-free. Thickness was found to be around $380 \mathrm{~nm}$. Deposition was attempted also on gold (120 nm sputtered on ultraflat Si wafers) at $10 \mathrm{~mA} / \mathrm{cm}^{2}$. In this case, precipitation of polygonal crystals on the surface was found to occur. Figure 1d depicts the typical appearance of a $\mathrm{Ru}$ layer plated on $\mathrm{Au}$ in the same conditions as the sample visible in Figure 1b. In this case, the use of stirring was attempted (300 rpm). However, crystal precipitation was found to occur both with and without stirring. The holes visible in Figure 1d are not due to delamination of the Ru layer, since there are no cracks or residues at the edges of the imperfections. Their formation takes place during deposition, with the precipitation of polygonal crystals on the surface of the electrode. $\mathrm{Ru}$ cannot grow where there are such crystals and, for this reason, water washing at the end of deposition can remove the crystals and can leave the polygonal holes visible in Figure $1 \mathrm{~d}$. Ru growth was observed also on the bottom of some of these imperfections. Indeed, if a crystal is released from the surface during deposition, $\mathrm{Ru}$ can grow inside the space left by the crystal itself. The depth of the holes present on the surface was evaluated via AFM to be between 450 and $500 \mathrm{~nm}$, value that corresponds to the thickness of the coating $(480 \mathrm{~nm})$. The presence of precipitates during $\mathrm{Ru}$ deposition in ILs has already been reported in the case of BMIM containing electrolytes. ${ }^{34}$ It was hypothesized, for BMIM based baths, that compounds of the type $\mathrm{RuX}_{\mathrm{x}} \mathrm{Y}_{3-\mathrm{x}}$ $\left(\mathrm{X}=\mathrm{NTf}_{2}\right.$ or $\mathrm{PF}_{6}, \mathrm{Y}=\mathrm{Cl}$ and $\mathrm{x}$ can be $\left.0-3\right)$ are responsible of the phenomenon, which takes place at concentrations higher than $15 \mathrm{mM}$ $\mathrm{Ru}(\mathrm{III})$ in BMIMNTf 2 and $40 \mathrm{mM} \mathrm{Ru}(\mathrm{III})$ in $\mathrm{BMIMPF}_{6}$. In the case of $\mathrm{ChCl} / \mathrm{EG}$, it seems that a similar phenomenon takes place. Crystals precipitation on the surface depends however on the substrate, since no crystals were observed in the case of deposition on $\mathrm{Cu}$. It is possible that only some substrates catalyze crystal formation, indicating the presence of an electrochemical mediated precipitation mechanism.
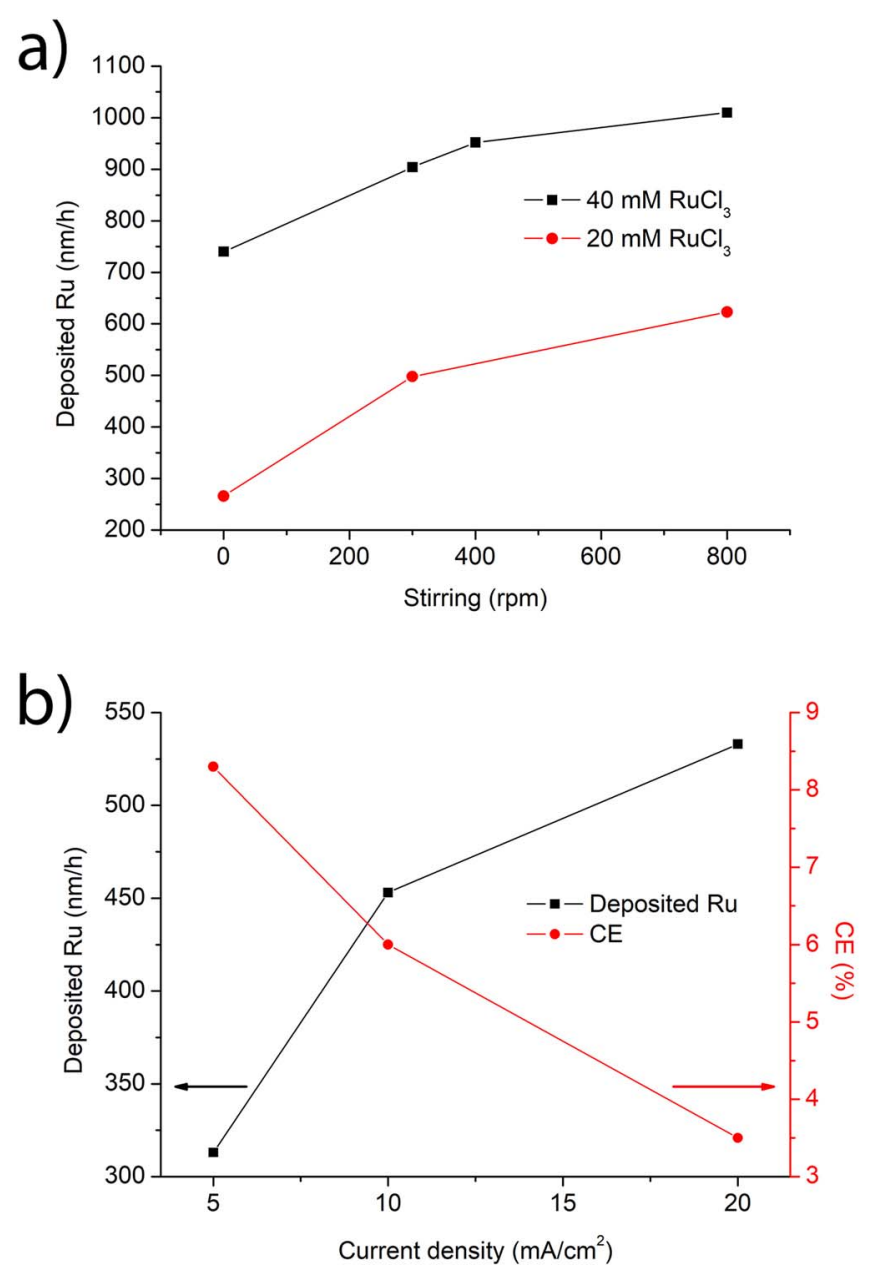

Figure 2. Stirring vs. grow rate relationship at $10 \mathrm{~mA} / \mathrm{cm}^{2}$ (a); current density vs. grow rate relationship at constant stirring rate $(300 \mathrm{rpm})$ and $20 \mathrm{mM} \mathrm{RuCl}_{3}$ $+800 \mathrm{mM}$ SA (b).

Pores formation was observed also decreasing $\mathrm{RuCl}_{3}$ concentration to $30 \mathrm{mM}$, but it was not observed at $20 \mathrm{mM}$ (Figure 7). This concentration was therefore employed to avoid the problem and to extend the range of usable substrates. As visible from Figure 1c, decrease of $\mathrm{Ru}$ (III) concentration from $40 \mathrm{mM}$ to $20 \mathrm{mM}$ worsened plating rate but improved morphology of the layer on Au.

Influence of stirring on the deposition rate was investigated as well. Figure 2a describes the relationship between stirring level applied and plating rate, keeping constant the current density at $10 \mathrm{~mA} / \mathrm{cm}^{2}$. As expected, deposition rate was considerably enhanced by high stirring levels. Solution agitation improved ions replenishment in proximity of the electrode, which was strongly limited by diffusion due to the low $\mathrm{Ru}$ concentration present in the electrolyte. To evaluate the effect of current density on plating rate and cathodic efficiency (CA), stirring was fixed to $300 \mathrm{rpm}$. Figure $2 \mathrm{~b}$ describes the results obtained. High currents accelerated Ru deposition but strongly decreased cathodic efficiency. At low plating rates, e.g. $5 \mathrm{~mA} / \mathrm{cm}^{2}$, cathodic efficiencies over $8 \%$ can be obtained. Figure 7 shows the results obtained plating $\mathrm{Ru}$ on Au using optimized parameters. In particular, the sample visible in Figure $7 \mathrm{e}$ was obtained using a $20 \mathrm{mM} \mathrm{RuCl}_{3}$ solution with $800 \mathrm{mM}$ $\mathrm{SA}, 300 \mathrm{rpm}$ stirring, $10 \mathrm{~mA} / \mathrm{cm}^{2}$ and $90 \mathrm{~min}$ deposition. Thickness of the Ru layer was measured and it was found to be $790 \mathrm{~nm}$, in conformity with the grow rates depicted in Figure 2a.

Electrolytes characterization.-The $\mathrm{Ru}$ containing electrolyte was characterized from the electrochemical point of view by performing conductivity measures and voltammetric studies. Figure 3 a describes the correlation between conductivity and temperature for 

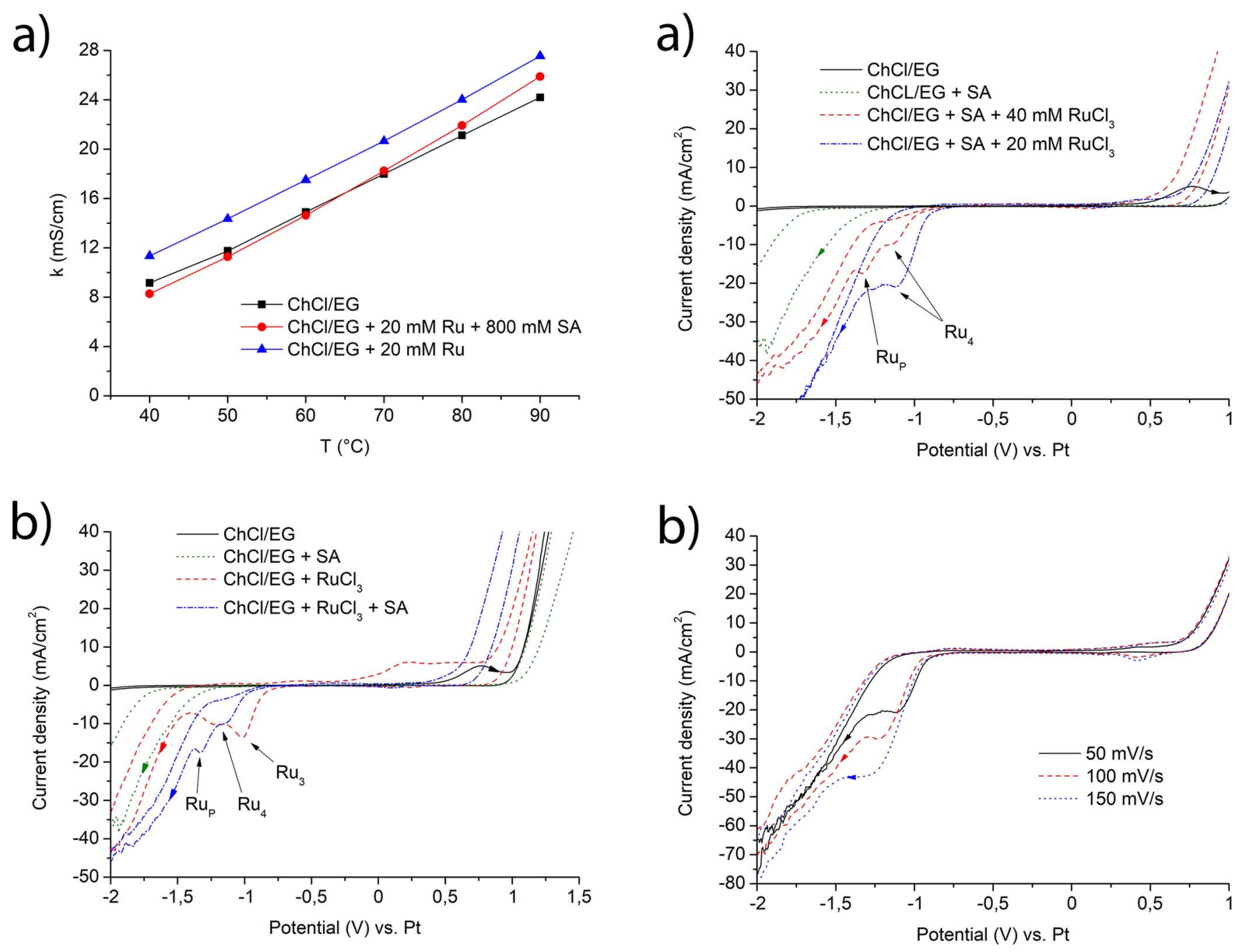

Figure 3. Conductivity vs. temperature for pure DES, DES + Ru and DES + $\mathrm{Ru}+\mathrm{SA}$ (a); cyclic voltammetry (WE: glassy carbon, RE: Pt, CE: graphite, $\mathrm{T}=80^{\circ} \mathrm{C}$ ) acquired at $50 \mathrm{mV} / \mathrm{s}$ for DES, DES + SA, DES + Ru and DES + $\mathrm{Ru}+\mathrm{SA}(\mathrm{b})$.

the $\mathrm{ChCl} / \mathrm{EG}$ DES, DES $+20 \mathrm{mM} \mathrm{Ru}$ and DES $+20 \mathrm{mM} \mathrm{Ru}+$ $800 \mathrm{mM}$ SA. Pure DES presents values of conductivity typical of 1:2 molar mixtures of $\mathrm{ChCl}$ and $\mathrm{EG} .{ }^{38}$ Addition of $20 \mathrm{mM} \mathrm{RuCl}_{3}$ slightly improves conductivity, as expected from the addition of metallic ions with high mobility to the DES, which is in turn characterized by low ionic mobility and conductivity. Conversely, the presence of SA together with $\mathrm{RuCl}_{3}$, results in values of conductivity analogous to the pure DES. This indicates that SA poorly dissociates in the electrolyte.

Voltammetric tests were performed to understand $\mathrm{Ru}$ deposition mechanism from $\mathrm{ChCl} / \mathrm{EG}$. $\mathrm{ChCl} / \mathrm{EG}$, in accordance to existing literature, ${ }^{38,39}$ presents an electrochemical window of $-2 /+1.1 \mathrm{~V}$ vs. $\mathrm{Pt}$, compatible with the electrodeposition of many metals. Addition of SA was found to strongly narrow the potential window on the cathodic side of the voltammetric diagram (Figure 3b), with parasitic reactions starting at a potential around $-1200 \mathrm{mV}$ vs. Pt. When $\mathrm{RuCl}_{3}$ was added to the electrolyte, the appearance of two distinct features was observed. The first one, marked with $\mathrm{Ru}_{3}$ in Figure $3 \mathrm{~b}$, was found to start around $-750 \mathrm{mV}$ and presented a peak at $-1000 \mathrm{mV}$. $\mathrm{Ru}_{3}$ was associated with reduction of the $\mathrm{Ru}^{3+}$ ions present in the solution. The second feature, marked with $\mathrm{Ru}_{4}$ in Figure $3 \mathrm{~b}$, presented a peak at $-1200 \mathrm{mV}$. Such peak was associated with reduction of $\mathrm{Ru}^{4+}$ ions. It was reported ${ }^{18,36}$ that commercial $\mathrm{RuCl}_{3}$ contains, as a consequence of natural oxidation, $\mathrm{Ru}(\mathrm{IV})$ species. Furthermore, the heat-treatment performed on the $\mathrm{RuCl}_{3}$ probably slightly changed the

Figure 4. Cyclic voltammetry (WE: glassy carbon, RE: Pt, CE: graphite, $\mathrm{T}=$ $80^{\circ} \mathrm{C}$ ) acquired at $50 \mathrm{mV} / \mathrm{s}$ for DES, DES + SA, DES + SA + Ru $40 \mathrm{mM}$ and $\mathrm{DES}+\mathrm{SA}+\mathrm{Ru} 20 \mathrm{mM}$ (a); voltammetries (WE: glassy carbon, RE: Pt, CE: graphite, $\mathrm{T}=80^{\circ} \mathrm{C}$ ) acquired at different speeds for DES + SA + Ru $20 \mathrm{mM}$ (b).

ratio $\mathrm{Ru}^{3+} / \mathrm{Ru}^{4+}$ in favor of the $\mathrm{Ru}(\mathrm{IV})$ moieties. For these reasons, it is somewhat expected to observe both $\mathrm{Ru}^{3+}$ and $\mathrm{Ru}^{4+}$ reduction from the voltammetry performed. If SA $(800 \mathrm{mM})$ was present in the solution together with $\mathrm{RuCl}_{3}, \mathrm{Ru}_{3}$ was not observed anymore. As evident from Figure $3 \mathrm{~b}$, only $\mathrm{Ru}_{4}$ is visible in the voltammetry of the $40 \mathrm{mM} \mathrm{RuCl}_{3}+800 \mathrm{mM} \mathrm{SA}$ solution. In this case, $\mathrm{Ru}_{4}$ peak was found at $-1200 \mathrm{mV}$, while the beginning of the reduction process was individuated around $-900 \mathrm{mV}$. It can be observed from Figure $3 \mathrm{~b}$ that in the presence of $\mathrm{RuCl}_{3}$ alone, the limiting current at potentials over $-1500 \mathrm{mV}$ roughly corresponds to the one of DES + SA. Conversely, when $\mathrm{RuCl}_{3}$ and SA are present at the same time, limiting current is comparatively higher. In accordance with what observed during the electrodeposition experiments performed in $\mathrm{Ru}^{3+}$ containing DES, no metallic Ru deposition was observed in correspondence of the onset potential of $\mathrm{Ru}_{3}(-750 \mathrm{mV}$ vs. $\mathrm{Pt})$. Conversely, $\mathrm{Ru}$ deposition was observed in correspondence of the onset potential of $\mathrm{Ru}_{4}(-900 \mathrm{mV}$ vs. $\mathrm{Pt}$ ). Considering this, and due to the presence of a single cathodic feature $\left(\mathrm{Ru}_{4}\right)$ in $\mathrm{Ru}(\mathrm{IV})$ containing solution, it is reasonable to infer that $\mathrm{Ru}$ ions directly reduce to metallic $\mathrm{Ru}$ from the tetravalent state, according to expression (1):

$$
\mathrm{Ru}^{4+}+4 \mathrm{e}^{-} \rightarrow \mathrm{Ru}^{0}
$$

Conversely, the trivalent state is unable to provide metallic $\mathrm{Ru}$ deposition. A possible reason for this phenomenon is the formation of 

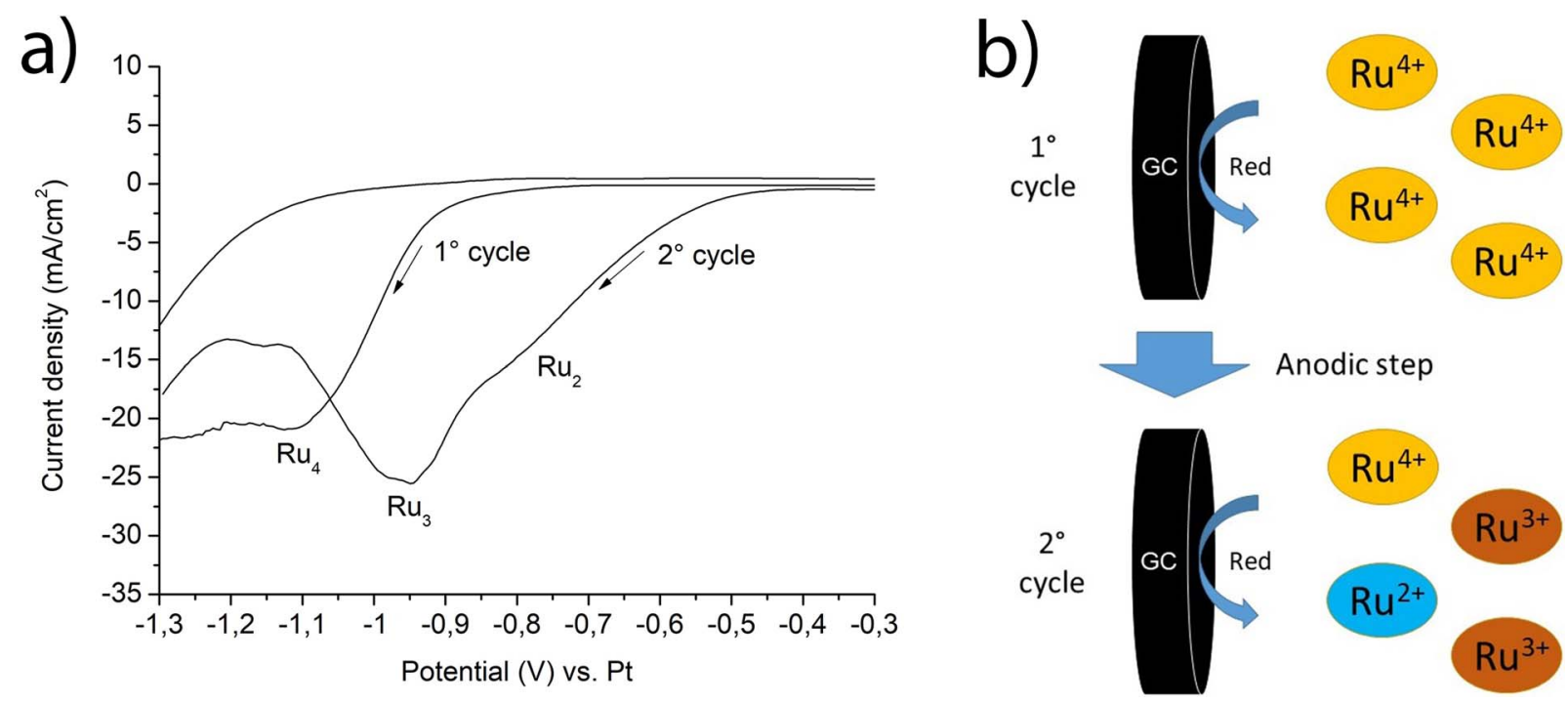

Figure 5. Multicycle voltammetry (WE: glassy carbon, RE: Pt, CE: graphite, $\mathrm{T}=80^{\circ} \mathrm{C}$ ) performed on a $20 \mathrm{mM} \mathrm{RuCl} 3_{3}$ solution in $\mathrm{DES}+\mathrm{SA}(\mathrm{a})$; explanation of the behavior observed during the second cycle (b).

very stable complexes with chloride ions, as already observed in the case of BMIM chloride based ILs by Jayakumar et al. ${ }^{34} \mathrm{Ru}_{3}$ peak can therefore be associated to the electroreduction of such $\mathrm{Ru}(\mathrm{III})$ complexes to valence states higher than 0 . In this context, the redox couple $\mathrm{Ru}(\mathrm{III}) / \mathrm{Ru}(\mathrm{n})$, with $\mathrm{n}>0$, presents a potential higher than the $\mathrm{Ru}(\mathrm{IV}) / \mathrm{Ru}(0)$ couple. Finally, a peculiar feature $\left(\mathrm{Ru}_{\mathrm{P}}\right)$ was observed in the case of the $\mathrm{RuCl}_{3}+\mathrm{SA}$ solution. This peak was associated with the electroprecipitation of chloride containing compounds on the surface of the electrode, which may be at the base of the morphology observed in Figure 1d. No significant anodic peaks were individuated both in presence and absence of SA in correspondence of the cathodic features observed, indicating a strong irreversibility of the electroreduction process. The anodic feature visible around $+250 \mathrm{mV}$ vs. $\mathrm{Pt}$ in Figure $3 \mathrm{~b}$ was observed only in the case of the $\mathrm{RuCl}_{3}$ containing electrolyte, without SA. Such peak can be associated to the possible oxidation of the $\mathrm{Ru}(\mathrm{III})$ chloride complexes previously hypothesized.

Figure $4 \mathrm{a}$ shows the effect of $\mathrm{RuCl}_{3}$ concentration on the voltammetry. It is evident from the graph that $\mathrm{R}_{\mathrm{P}}$ disappears in the case of the $20 \mathrm{mM} \mathrm{RuCl}_{3}$ electrolyte, while $\mathrm{R}_{4}$ is always present. It is fundamental to notice that no crystals precipitation was observed at $20 \mathrm{mM}$ $\mathrm{RuCl}_{3}$. The lack of the $\mathrm{Ru}_{\mathrm{P}}$ peak in the $20 \mathrm{mM} \mathrm{RuCl}$ graph constitutes a reasonable evidence of its connection with chloride containing species precipitation. Figure $4 \mathrm{~b}$ depicts the effect of scan speed on the voltammetries performed on the DES + $800 \mathrm{mM} \mathrm{SA}+20 \mathrm{mM} \mathrm{RuCl}_{3}$ solution. As expected, the cathodic peak associated to $\mathrm{Ru}^{4+}$ reduction slightly moves to more negative potentials by increasing scan speed. Moreover, its intensity increases.

Figure 5a shows a voltammetry analogous to the one depicted in Figure $4 \mathrm{a}$ for the DES $+800 \mathrm{mM} \mathrm{SA}+20 \mathrm{mM} \mathrm{RuCl}_{3}$ solution. In this case, however, a second cycle was performed. It can be immediately seen that, during the second cycle, two new peaks appear $\left(\mathrm{Ru}_{2}\right.$ and $\left.\mathrm{Ru}_{3}\right) . \mathrm{Ru}_{3}$, as previously said, can be associated with $\mathrm{Ru}^{3+}$ reduction, while $\mathrm{Ru}_{2}$ can be attributed to $\mathrm{Ru}^{2+}$ reduction. The reason for this behavior is described in Figure 5b. During the first cycle, $\mathrm{Ru}^{4+}$ is the only reducible specie. For this reason, when the GC electrode works as cathode, only the single $\mathrm{Ru}_{4}$ reduction peak can be observed (Figure 5b). As the analysis proceeds, the GC electrode continue working as cathode and $\mathrm{Ru}^{4+}$ is reduced to $\mathrm{Ru}^{3+}, \mathrm{Ru}^{2+}$ and $\mathrm{Ru}^{0}$. The two (III) and (II) valent ions stay in close proximity of the GC electrode due to the lack of stirring and to the high viscosity of the DES. When the GC works as anode, no significant reactions take place due to the strong irreversibility of the system. During the second cycle, when the $\mathrm{GC}$ again works as cathode, $\mathrm{Ru}^{2+}$ and $\mathrm{Ru}^{3+}$ ions are reduced (Figure 5b). This yields the two peaks $\mathrm{Ru}_{2}$ and $\mathrm{Ru}_{3}$. Presence of $\mathrm{Ru}^{2+}$ can be easily inferred from the color of the electrolyte in close proximity of the GC surface. When the electrode is removed from the solution at the end of the test, the DES present on the surface appears green. $\mathrm{Ru}^{2+}$ ions are reported to be blue. ${ }^{40}$ When blue is combined with the yellowish-brown tinge of the $\mathrm{Ru}^{4+}$ containing solution (insert of Figure 6), the final result is a green color. The behavior observed constitutes another evidence to support the presence of $\mathrm{Ru}$ in the (IV) valence state in the electrolyte.

The most evident effect induced by the presence of SA on the $\mathrm{RuCl}_{3}$ solution is the change in color, which strictly correlates with the electronic properties of the species present in solution. The insert presented in Figure 6 visually describes the phenomenon, while the UV-VIS spectra depicted in the same image quantify the alterations of the electronic transitions. Prepared electrolytes $(\mathrm{ChCl} / \mathrm{EG}+$ $800 \mathrm{mM} \mathrm{SA}, \mathrm{ChCl} / \mathrm{EG}+20 \mathrm{mM} \mathrm{RuCl}_{3}$ and $\mathrm{ChCl} / \mathrm{EG}+800 \mathrm{mM}$ $\mathrm{SA}+20 \mathrm{mM} \mathrm{RuCl}{ }_{3}$ ) were diluited with the pure DES to avoid saturation of the absorbance signal. $\mathrm{ChCl}+800 \mathrm{mM} \mathrm{SA}$ was diluited 1:4 vol., resulting in a concentration of $200 \mathrm{mM} \mathrm{SA}$. ChCl/EG + $20 \mathrm{mM} \mathrm{RuCl}_{3}$ was diluited 1:100 vol., resulting in a concentration of $0.2 \mathrm{mM} \mathrm{RuCl}_{3}$. Finally, ChCl/EG $+800 \mathrm{mM} \mathrm{SA}+20 \mathrm{mM} \mathrm{RuCl}_{3}$

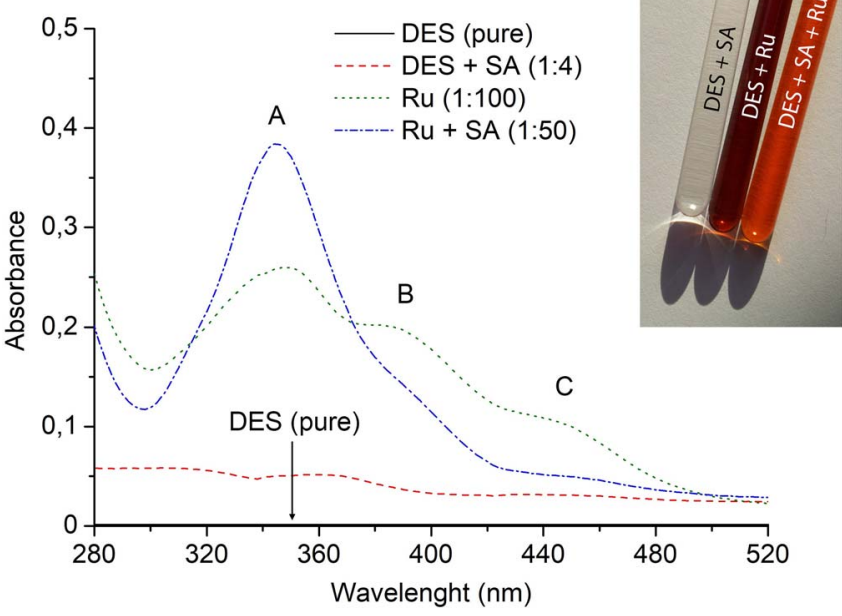

Figure 6. UV-VIS analysis and visual appearance (insert) of the most significant electrolytes. 

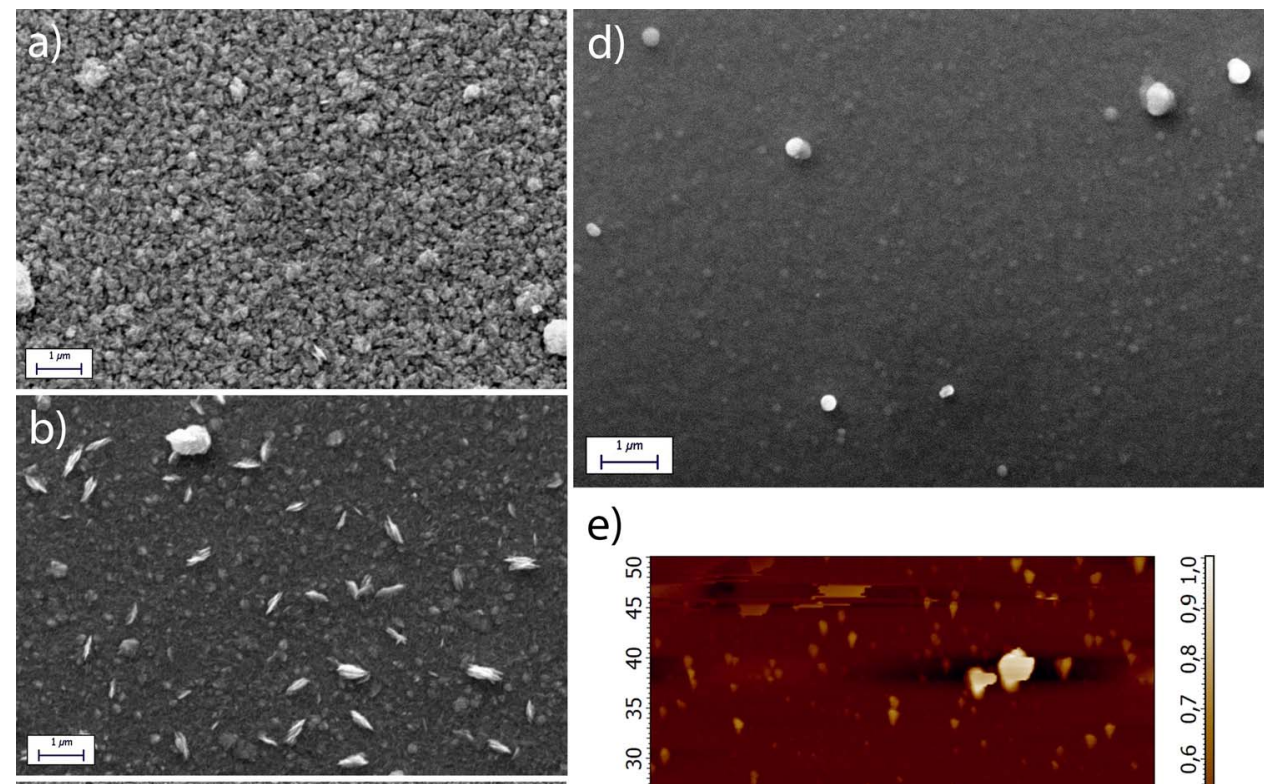

e)
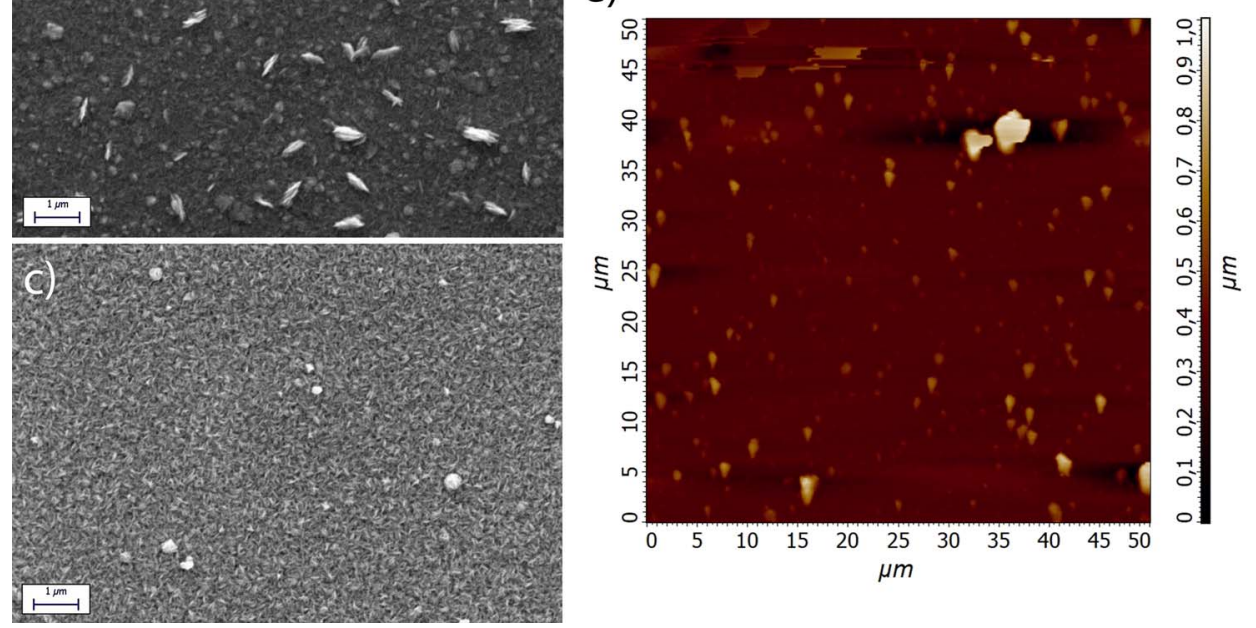

Figure 7. SEM morphology of Ru growth on $\mathrm{Au} / \mathrm{Si}$ at $5 \mathrm{~mA} / \mathrm{cm}^{2}$ (a), $10 \mathrm{~mA} / \mathrm{cm}^{2}$ (b) $20 \mathrm{~mA} / \mathrm{cm}^{2}$ (c); SEM morphology of a Ru layer growth on Au/Si at $-1000 \mathrm{mV}$ vs. Pt (d); AFM analysis of a Ru layer growth on $\mathrm{Au} / \mathrm{Si}$ at $10 \mathrm{~mA} / \mathrm{cm}^{2}, 300 \mathrm{rpm}$ and $90 \mathrm{~min}$ as plating time (e); optimized electrolyte (800 mM SA + $20 \mathrm{mM} \mathrm{RuCl}_{3}$ ) was employed in all cases.

was diluited 1:50 vol., resulting in a concentration of $0.4 \mathrm{mM} \mathrm{RuCl} 3$ and $16 \mathrm{mM}$ SA. Pure $\mathrm{ChCl} / \mathrm{EG}$ and $\mathrm{ChCl} / \mathrm{EG}+\mathrm{SA}$ does not present significant UV-VIS peaks. The same two solutions, additivated with $\mathrm{RuCl}_{3}$, present three distinct peaks. Such three features, namely A, $\mathrm{B}$ and $\mathrm{C}$ in Figure 6, seem to be present for both solutions, either containing SA or not. Peak A was observed at $345 \mathrm{~nm}$, peak B around $390 \mathrm{~nm}$ and peak $\mathrm{C}$ at $448 \mathrm{~nm}$. Peak assignation is not immediate, since all the literature available describes the $\mathrm{Ru}$ electronic transitions taking place in aqueous environment. ${ }^{18}$ The usage of $\mathrm{ChCl} / \mathrm{EG}$ in place of water as electrolyte is however expected to strongly alter the position of UV-VIS peaks due to the substitution of $\mathrm{H}_{2} \mathrm{O}$ ligands with chloride ions around $\mathrm{Ru}$ within the coordination shell. For this reason, comparison with equivalent water electrolytes is difficult. Some considerations can be however done by correlating the UV-VIS peaks with the composition of the solutions analyzed. First, the presence of a bridged complex similar to $\mu$-nitridobisaquatetrachlororuthenate can be excluded. Campbell et al..$^{41}$ report the main electronic transitions of $\left[\mathrm{Ru}_{2}(\mu-\mathrm{N})\left(\mathrm{H}_{2} \mathrm{O}\right)_{2} \mathrm{Cl}_{8}\right]^{3-}$ in the $360-400 \mathrm{~nm}$ range and around $300 \mathrm{~nm}$. None of these peaks can be associated with the features visible in the $\mathrm{DES}+\mathrm{RuCl}_{3}$ case, because no SA is present in the solution and thus no bridged complex can form. Also in the case of the DES $+\mathrm{SA}+\mathrm{RuCl}_{3}$ solution the peaks cannot be directly associated. Formation of the bridged complex is expected to strongly vary the position of the electronic transitions. In the case of DES + SA + $\mathrm{RuCl}_{3}$, however, the position of $\mathrm{A}, \mathrm{B}$ and $\mathrm{C}$ looks identical to DES + $\mathrm{RuCl}_{3}$. For this reason, formation of a RuNRu bridged complex can be excluded. Other information can be extrapolated from the height of the peaks. As previously said, commercial $\mathrm{RuCl}_{3}$ is strongly contaminated by $\mathrm{Ru}(\mathrm{IV})$ species. ${ }^{18,36}$ It is therefore reasonable to state that the UV-VIS spectra visible in Figure 6 for the DES $+\mathrm{RuCl}_{3}$ so- lution is the result of the electronic excitation of both $\mathrm{Ru}^{3+}$ and $\mathrm{Ru}^{4+}$ containing species. After addition of SA, peak A intensity increases, while peak B and C intensity decreases. Since peak intensity can be correlated to the concentration of a particular specie by Lambert-Beer law, it can be reasonably stated that peak A is correlated to a moiety whose concentration increases by adding SA to DES $+\mathrm{RuCl}_{3}$. As demonstrated by the electrochemical behavior of the solution, such specie can be $\mathrm{Ru}^{4+}$ ions. Accordingly, the remaining peaks intensity decrease due to conversion of $\mathrm{Ru}^{3+}$ to $\mathrm{Ru}^{4+}$. Deposition of $\mathrm{Ru}$ in $\mathrm{ChCl} / \mathrm{EG}$ requires therefore the formation of $\mathrm{Ru}^{4+}$, in a way similar to what observed in the case of other ILs.

$\boldsymbol{R} \boldsymbol{u}$ layers characterization.- $\mathrm{Ru}$ layers obtained from the optimized electrolyte, containing $800 \mathrm{mM} \mathrm{SA}$ and $20 \mathrm{mM} \mathrm{RuCl}_{3}$, were characterized from the morphological and microstructural point of view. Initially, the effect of plating current on the surface morphology was investigated. Figures $7 \mathrm{a}, 7 \mathrm{~b}$ and $7 \mathrm{c}$ represent the SEM morphology of Ru deposits obtained at 5,10 and $20 \mathrm{~mA} / \mathrm{cm}^{2}$ respectively on $\mathrm{Au} / \mathrm{Si}$. A constant total charge of $27 \mathrm{C}$ was employed for deposition, resulting in plating times of $90 \mathrm{~min}\left(5 \mathrm{~mA} / \mathrm{cm}^{2}\right), 45 \mathrm{~min}$ $\left(10 \mathrm{~mA} / \mathrm{cm}^{2}\right)$ and $22 \mathrm{~min} 30 \mathrm{~s}\left(20 \mathrm{~mA} / \mathrm{cm}^{2}\right)$. Resulting thicknesses, which were employed to calculate $\mathrm{CE}$ in Figure 2b, were as follows: $470 \mathrm{~nm}\left(5 \mathrm{~mA} / \mathrm{cm}^{2}\right), 340 \mathrm{~nm}\left(10 \mathrm{~mA} / \mathrm{cm}^{2}\right)$ and $200 \mathrm{~nm}\left(20 \mathrm{~mA} / \mathrm{cm}^{2}\right)$. It can be observed that the coatings are always crack-free, with a microstructure that progressively refines moving from low to high currents (compatibly with the uneven thicknesses). Nodules can be observed on the surface for all the deposits. EDS point analysis performed on such nodules evidenced that they are mainly composed of $\mathrm{Ru}$, excluding thus precipitation of species (similarly to what observed 

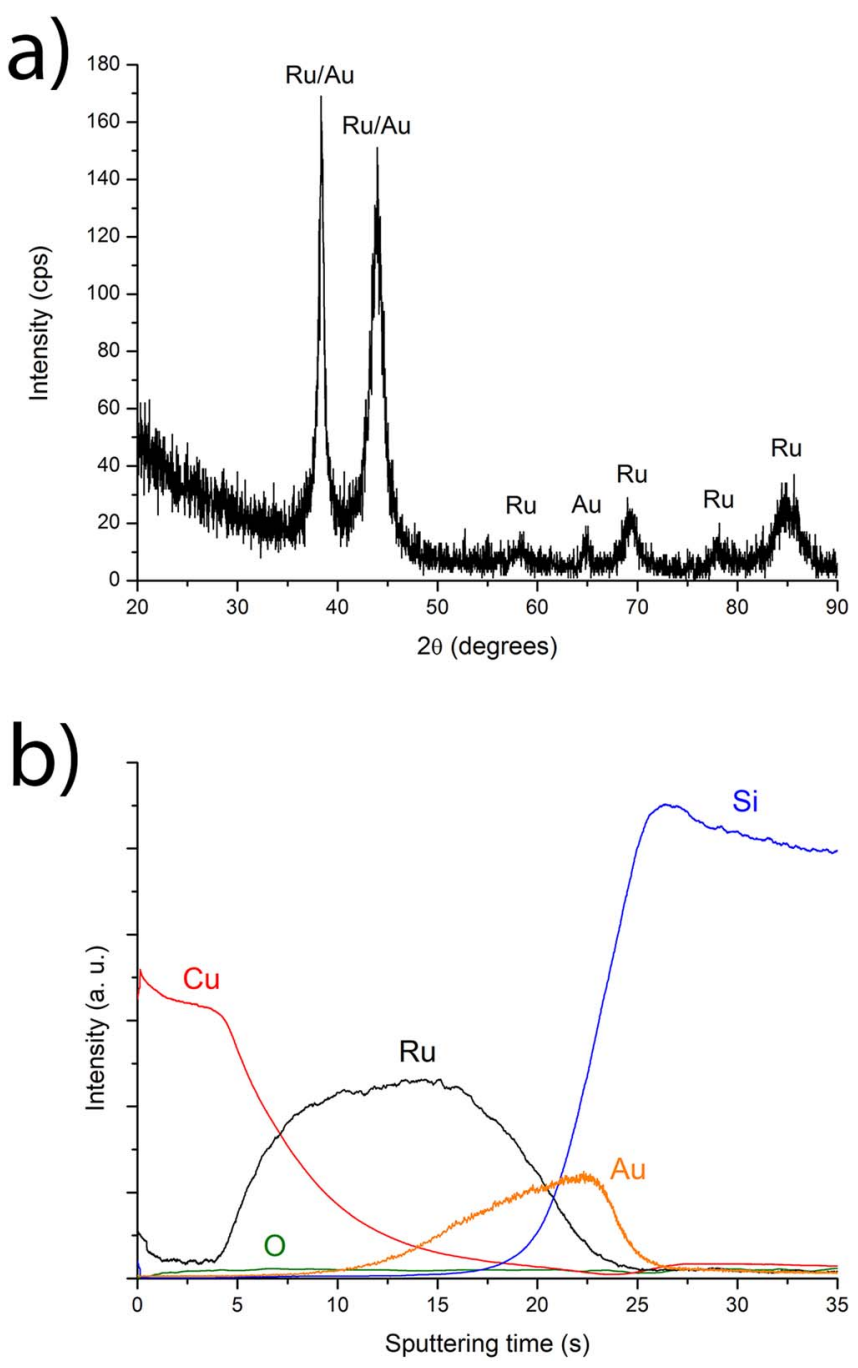

Figure 8. XRD of Ru growth on $\mathrm{Au} / \mathrm{Si}$ (a); GDOES of a Ru layer growth on $\mathrm{Au} / \mathrm{Si}$ (b); optimized electrolyte $\left(800 \mathrm{mM} \mathrm{SA}+20 \mathrm{mM} \mathrm{RuCl}_{3}\right.$ ) was employed in all cases.

in Figure 1d). Ru deposition from the DES $+\mathrm{SA}+\mathrm{RuCl}_{3}$ solution can be performed not only galvanostatically but also potentiostatically. As an example, Ru was deposited for $60 \mathrm{~min}$ at $-1000 \mathrm{mV}$ vs. Pt on Au/Si. Final thickness was $210 \mathrm{~nm}$, with the microstructure visible in Figure 7d. If the sample is compared with Figure 7c $(\mathrm{Ru}$ obtained at $20 \mathrm{~mA} / \mathrm{cm}^{2}$ presenting a similar thickness), it can be immediately noticed that the structure is highly nanocrystalline and the surface is considerably smoother. Also in this case, however, metallic nodules were present on the surface. It was observed that crack-free layers can be obtained up to $800 \mathrm{~nm}$ and more. Figure 7e reports the AFM analysis of a Ru coating deposited at $10 \mathrm{~mA} / \mathrm{cm}^{2}, 300 \mathrm{rpm}$ and $90 \mathrm{~min}$ as plating time. Thickness in this case is considerably high, $790 \mathrm{~nm}$. However, no cracks can be observed on the surface. Average roughness $R_{a}$ was measured from the AFM analysis, resulting in a value of $33 \mathrm{~nm}$ (on the $50 \mu \mathrm{m} \times 50 \mu \mathrm{m}$ area showed in Figure 7e). Such value is relatively low if compared with the $\mathrm{R}_{\mathrm{a}}$ of the uncoated $\mathrm{Au} / \mathrm{Si}$ substrate $(\sim 3 \mathrm{~nm})$.

$\mathrm{Ru}$ layers were analyzed also to assess their purity and lack of organic contamination. Figure 8 a shows the results obtained from XRD performed on a sample deposited on Au/Si. Only peaks related to phase pure metallic hcp Ru (JCPDS card 6-663) were observed during the analysis. The relatively high peak broadening observed in Figure 8a indicates a nanocrystalline structure. No peaks were observed for ruthenium oxides, whose absence was confirmed also
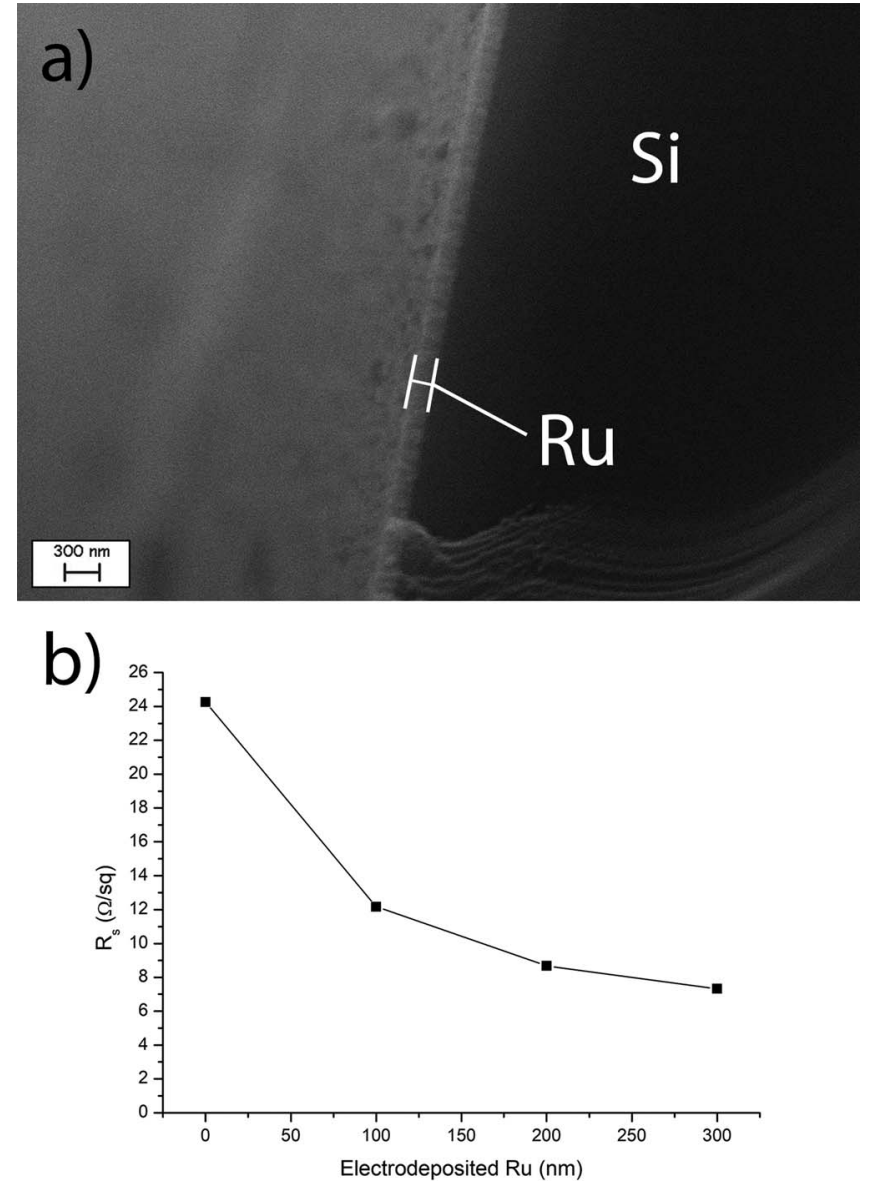

Figure 9. Section of a Ru layer deposited on $\mathrm{Ru} / \mathrm{Si}$ (a); sheet resistance vs. $\mathrm{Ru}$ thickness on Ru/Si (b); optimized electrolyte ( $\left.800 \mathrm{mM} \mathrm{SA}+20 \mathrm{mM} \mathrm{RuCl}_{3}\right)$ was employed in all cases.

by the extremely low intensity of the EDS oxygen peak observed. GDOES was performed as well on Ru plated on $\mathrm{Au} / \mathrm{Si}$. In this case, considering the reduced thickness of the $\mathrm{Ru}$ coating, a layer of copper was deposited on top to protect the surface from the initial plasma ignition (which may damage the Ru layer). A $1 \mu \mathrm{m}$ thick copper layer was therefore electrodeposited using a commercial acidic solution. After this step, the sample was inserted in the GDOES instrument. As noticeable from Figure 8b, the Ru layer signal is clearly observable between the $\mathrm{Au}$ layer and the $\mathrm{Cu}$ protective coating applied on the surface. Negligible oxygen contamination was observed via GDOES, confirming thus the purity of the Ru layer deposited.

Ruthenium, as stated in the introductory part, can be proficiently used as barrier layer in ICs interconnects. Considering this possible application, $\mathrm{Ru}$ layers obtained from $\mathrm{ChCl} / \mathrm{EG}$ were investigated from the electrical point of view to determine their sheet resistance. Ru was deposited on a Ru seed layer obtained by evaporation on Si. Figure 9a depicts the cross section of a Ru layer deposited on Ru/Si. Total thickness is $210 \mathrm{~nm}$, resulting from $10 \mathrm{~nm}$ of sputtered $\mathrm{Ru}$ and $200 \mathrm{~nm}$ of electrodeposited $\mathrm{Ru}$. Uniformity and adherence of the Ru coating are evident observing the morphology of the section. Figure $9 \mathrm{~b}$ reports the values of sheet resistance obtained for different thicknesses of electrodeposited $\mathrm{Ru}$. Values of thickness reported in Figure 9b does not refer to the total thickness of Ru (sputtered + electrodeposited), but only to the partial thickness of electrodeposited $\mathrm{Ru}$. For this reason, the sheet resistance value at $0 \mathrm{~nm}$ of deposited $\mathrm{Ru}$ corresponds to the sheet resistance of the sputtered Ru layer. It can be observed that, as expectable, sheet resistance decreases with increasing Ru thickness. Values of sheet resistance are compatible with existing literature for barrier layers deposited from sputtering. ${ }^{42}$ This demonstrates that the 
Ru layers obtained by deposition from the DES based electrolyte described in the present work have electrical properties comparable with $\mathrm{Ru}$ coatings obtained with a more expensive and less flexible technique like sputtering. In this context, by comparing sheet resistance values, it can be reasonably supposed that $\mathrm{Ru}$ layers deposited from $\mathrm{ChCl} / \mathrm{EG}$ meet the general requirements for barrier layer. ${ }^{43}$

\section{Conclusions}

Metallic ruthenium was successfully deposited for the first time from a choline chloride based deep eutectic solvent. Addition of sulfamic acid to the $\mathrm{Ru}(\mathrm{III})$ containing DES was found to trigger significant $\mathrm{Ru}$ electrodeposition, whereas the sulfamic acid free bath was unable to provide satisfactory plating. The main reason for this behavior, as evidenced by the electrochemical characterization performed on the electrolytes, was found in the oxidation of $\mathrm{Ru}$ (III) to $\mathrm{Ru}(\mathrm{IV})$. At concentrations of $20 \mathrm{mM}$ for $\mathrm{RuCl}_{3}$ and $800 \mathrm{mM}$ for $\mathrm{SA}, \mathrm{Ru}(\mathrm{IV}$ ) electroreduction was observed at potentials lower than $-900 \mathrm{mV}$ vs. Pt. Both galvanostatic and potentiostatic deposition from the same electrolyte yielded smooth and uniform $\mathrm{Ru}$ layers on $\mathrm{Au}$ and $\mathrm{Cu}$. Galvanostatically plated $\mathrm{Ru}$ coatings were found to be free from oxides and cracks up to a thickness around $800 \mathrm{~nm}$. The same coatings showed interesting electrical properties, analogous to layers obtained with more costly and less scalable techniques like sputtering. Ru electrodeposited from DES can therefore constitute, due to these favorable properties, an interesting material for interdiffusion barrier layers.

\section{Acknowledgments}

The authors acknowledge the contribution of G. Griffini (Politecnico di Milano), who measured sheet resistance of the $\mathrm{Ru}$ layers deposited from the electrolyte described in the text.

\section{ORCID}

R. Bernasconi (D) https://orcid.org/0000-0003-2193-8017

L. Magagnin (D) https://orcid.org/0000-0001-5553-6441

\section{References}

1. S. E. Livingstone, in Pergamon Texts in Inorganic Chemistry, vol. 25, p. 1163, Pergamon (1973).

2. P. C. Hydes, Platin. Met. Rev., 24, 50 (1980).

3. L. Shishkina, O. Lokshtanova, and S. Karabanov, Coatings, 2,1 (2012).

4. T. N. Arunagiri, Y. Zhang, O. Chyan, M. El-Bouanani, M. J. Kim, K. H. Chen, C. T. Wu, and L. C. Chen, Appl. Phys. Lett., 86, 1 (2005).

5. M. Damayanti, T. Sritharan, S. G. Mhaisalkal, E. Phoon, and L. Chan, J. Electrochem. Soc., 153, J41 (2006).

6. H. Liu, C. Song, L. Zhang, J. Zhang, H. Wang, and D. P. Wilkinson, J. Power Sources, 155, 95 (2006).
7. H. Over, Chem. Rev., 112, 3356 (2012).

8. D. Josell, D. Wheeler, C. Witt, and T. P. Moffat, Electrochem. Solid-State Lett., 6, C143 (2003).

9. L. G. Wen, P. Roussel, O. V. Pedreira, B. Briggs, B. Groven, S. Dutta, M. I. Popovici, N. Heylen, I. Ciofi, and K. Vanstreels, ACS Appl. Mater. Interfaces, 8, 26119 (2016).

10. T. Oku, E. Kawakami, M. Uekubo, K. Takahiro, S. Yamaguchi, and M. Murakami, Appl. Surf. Sci., 99, 265 (1996).

11. M. Y. Kwak, D. H. Shin, T. W. Kang, and K. N. Kim, Thin Solid Films, 339, 290 (1999).

12. Y. Du, in Binary Evaluations: $\mathrm{Cu}-\mathrm{Ru}$, G. Effenberg, Editor, MSI, Materials Science International Services GmbH, Stuttgart (2002).

13. H. Wojcik, M. Junige, W. Bartha, M. Albert, V. Neumann, U. Merkel, A. Peeva, J. Gluch, S. Menzel, F. Munnik, R. Liske, D. Utess, I. Richter, C. Klein, H. J. Engelmann, P. Ho, C. Hossbach, and C. Wenzel, J. Electrochem. Soc., 159, H166 (2012).

14. C. R. K. Rao and D. C. Trivedi, Coord. Chem. Rev., 249, 613 (2005).

15. S. M. Karabanov and O. G. Lokshtanova, Russ. J. Appl. Chem., 81, 1000 (2008)

16. G. S. Reddy and P. Taimsalu, Trans. IMF, 47, 187 (1969).

17. D. K. Oppedisano, L. A. Jones, T. Junk, and S. K. Bhargava, J. Electrochem. Soc., 161, D489 (2014).

18. E. A. Seddon and K. R. Seddon, The Chemistry of Ruthenium, Elsevier Science Inc., Amsterdam, (1984).

19. J.-J. Jow, H.-J. Lee, H.-R. Chen, M.-S. Wu, and T.-Y. Wei, Electrochim. Acta, 52, 2625 (2007).

20. V. D. Patake, C. D. Lokhande, and O. S. Joo, Appl. Surf. Sci., 255, 4192 (2009).

21. Y. Yang, A. Jo, Y. Lee, and C. Lee, Sensors Actuators B Chem., 255, 316 (2018).

22. R. Bernasconi and L. Magagnin, Surf. Eng., 33, 131 (2017).

23. E. L. Smith, A. P. Abbott, and K. S. Ryder, Chem. Rev., 114, 11060 (2014).

24. A. P. Abbott and K. J. McKenzie, Phys. Chem. Chem. Phys., 8, 4265 (2006).

25. R. Bernasconi, G. Panzeri, A. Accogli, F. Liberale, L. Nobili, and L. Magagnin, in Progress and Developments in Ionic Liquids, InTech (2017).

26. S. Ghosh and S. Roy, Surf. Coatings Technol., 238, 165 (2014).

27. A. P. Abbott, K. El Ttaib, K. S. Ryder, and E. L. Smith, Trans. IMF, 86, 234 (2008).

28. M. A. Miller, J. S. Wainright, and R. F. Savinell, J. Electrochem. Soc., 164, A796 (2017).

29. P. Cojocaru, L. Magagnin, E. Gomez, and E. Valles, Mater. Lett., 65, 3597 (2011).

30. Y. H. You, C. D. Gu, X. L. Wang, and J. P. Tu, Surf. Coatings Technol., 206, 3632 (2012).

31. A. P. Abbott, K. El Ttaib, G. Frisch, K. S. Ryder, and D. Weston, Phys. Chem. Chem. Phys., 14, 2443 (2012)

32. O. Raz, G. Cohn, W. Freyland, O. Mann, and Y. Ein-Eli, Electrochim. Acta, 54, 6042 (2009).

33. O. Mann, W. Freyland, O. Raz, and Y. Ein-Eli, Chem. Phys. Lett., 460, 178 (2008).

34. M. Jayakumar, K. A. Venkatesan, T. G. Srinivasan, and P. R. Vasudeva Rao, Electrochim. Acta, 54, 6747 (2009).

35. M. Jayakumar, K. A. Venkatesan, R. Sudha, T. G. Srinivasan, and P. R. Vasudeva Rao, Mater. Chem. Phys., 128, 141 (2011).

36. J. A. Broomhead and G. Charles, Inorg. Synth., 28, 338 (1990).

37. G. Inzelt, in Handbook of Reference Electrodes, G. Inzelt, A. Lewenstam, and F. Scholz, Editors, p. 331, Springer Berlin Heidelberg, Berlin, Heidelberg (2013).

38. R. Bernasconi, M. Zebarjadi, and L. Magagnin, J. Electroanal. Chem., 758, 163 (2015).

39. A. Popescu, V. Constantin, A. Cojocaru, and M. Olteanu, Rev. Chim. (Bucharest), 62, 206 (2011).

40. G. A. Rechnitz, Inorg. Chem., 1, 953 (1962).

41. J. R. Campbell and R. J. H. Clark, J. Chem. Soc. Dalt. Trans., 1239 (1981).

42. M. Damayanti, T. Sritharan, S. G. Mhaisalkar, E. Phoon, and L. Chan, J. Mater. Res., 22, 2505 (2007).

43. M.-A. Nicolet, Thin Solid Films, 52, 415 (1978). 